\title{
Scientific and Methodological Support for Modern Educational Technology Introduction into the Educational Process
}

\author{
Lyudmila N. Nugumanova*, Galiya A. Shaykhutdinova, and Tatyana V. Yakovenko \\ State Autonomous Educational Institution of Supplementary Vocational Education "Tatarstan Institute \\ of Education Development", Kazan, Russia
}

\begin{abstract}
In the article the authors consider opportunities for scientific and methodological support of contemporary education digitization. The purpose of the article is to identify scientific and methodological support resources for developing specific recommendations to teachers on tackling education-related problems in the digital educational environment. When designing scientific and methodological support tools meant to facilitate introduction of modern educational technologies into the advanced teacher training process, the authors were basing on the principles of globalization and regionalization, technology continuity and discreteness, flexibility and availability. Consideration of the above mentioned principles permits to: introduce technologies applied in the global educational space, taking into account regional potential and student needs; select and combine individual factors of pedagogical technologies being based on assessment of their didactic efficiency under the conditions of a concrete educational process; adapt the technologies to teaching conditions, student cohort, budget, time and other circumstances in a timely and mobile manner. The article is meant for the academic teaching staff of institutes of supplementary teacher education, postgraduate and external $\mathrm{PhD}$ students, teachers and all those who take interest in problems of contemporary education.
\end{abstract}

The contemporary education is upon the look for new ways for introducing innovative educational technologies. Globalization, ecologization of education, lifelong learning, digitalization, gamification - all these global trends could not help but take a toll on Russian education. Problems that arose within the period of a special sanitary and epidemiological regime demonstrated unreadiness of the Russian school to work under the conditions of distance learning. There was no scientific and methodological support for the process of preparing children and their parents for the remote learning. Detected was deficiency of technical means, Internet opportunities etc. With the course of this period the situation normalized. Teachers, parents and students managed to adapt to it, but a lot of problems could have been avoided, if the process of switch to distance learning had instantaneously got scientific and methodological support.

\footnotetext{
${ }^{*}$ Corresponding author: lyudmila.nugumanova@tatar.ru
} 
The scientific and methodological support is a process of developing organizational and technological, as well as pedagogical mechanisms of bringing scientific results to practical education. The scientific and methodological support results in concrete recommendations to teachers on solving definite tasks. [3] In this respect, the key requirement to them is to reflect the consequence of identified objective pedagogical laws and theories transferred to the level of specific methodologies. [4] We shall turn our attention to the technological aspect.

The transfer to the technological level of the educational process design permits to educate students able to:

- find their feet in changing life circumstances by independently acquiring necessary knowledge and putting it to use for tackling various problems arising, so as to be able to find a niche for themselves during their lifetime;

- independently do critical thinking, see the evolving problems and search for their rational solution using modern technologies; clearly understand where and in what way the knowledge acquired by them can be applied; generate new ideas and think creatively;

- work with information appropriately: collect facts required for solving certain problem, analyse them, make necessary generalizations, correlations with analogous or alternative solutions, determine statistic and logical patterns, draw well founded conclusions, apply gained experience for diagnosing and handling new problems;

- be a communicative, sociable person in various social groups, be able to team up in different spheres, different circumstances, preventing any conflict situations or featly disentangling from them;

- independently work at raising their own morality, intellect, cultural level [1].

It is extremely difficult to form a personality complying with the described requirements using the traditional approach to the education. Therefore, technology introduction into the educational process must be conscious and imply full understanding of how each technology can facilitate the student's development, plying with new knowledge and forming of competences needed for successful life in today's society.

We believe that the teacher's choice of the respective technology should rest upon the following principles:

- globalization and regionalization; the principle permits to introduce technologies used in the global educational space, taking into account regional potential and student needs;

- technology continuity and discreteness; in each case the problem of selecting and combining individual factors of a pedagogical technology can and must be solved on the basis of unbiased assessment of their didactic efficiency under the conditions of a concrete educational process;

- flexibility and availability, that is, its ability to adapt to teaching conditions, student cohort, budget, time and other circumstances in a timely and mobile manner, to contribute to creating motivation for independent knowledge acquisition.

Contrary to lay belief, the contemporary teacher is mobile and ready for innovations and introduction of new information technologies. The following technologies are most frequently used in the educational process by teachers in the Republic of Tatarstan (the list has been compiled based on opinion poll of advanced training course participants): information and communication technologies, critical thinking improvement technologies, project technologies, case technologies and others. As may be inferred from the poll, the complete range of technologies is now being introduced into the educational process at schools.

Distance learning technologies are the leaders among the aforenamed technologies. In the modern context all the teachers are skilled in using them in their activities. The advantages of remote educational technologies are: absence of borders, effectiveness, common availability, mobility. However, not everybody understands the effectiveness of this or that electronic resource, its technological capabilities. In this regard, the process of remote 
technology introduction into the educational process requires scientific and methodological support.

For years Tatarstan organisations of supplementary vocational education have been purposively forming and developing teacher's professional competences in the sphere of communication and information technologies when building the educational process.

The scientific support of this process consists in designing a digital transformation model for the educational organisation's environment, depending on its material and technical resources, competence level of the teaching staff, remoteness from the center. The complexity of the educational sphere transformation process lies in the fact that every school and its educational environment are unique in their nature, although they are built according to general concepts. From this perspective, the same resources and efforts put into digital transformation do not give identical or even close effect of reorganization of internal pedagogical processes at school. The challenge for Tatarstan Institute of Education Development is to create a generalized model of the teacher's digital literacy improvement. To achieve this, a number of scientific and methodological aids have been worked out for teachers and students. These aids permit to solve teaching and educational problems and create conditions for the student's independent work using digital environment. The scientific and methodological package includes recommended textbooks and teaching guides, method books, projects and recommendations, intra-term tests and quizzes, evaluation criteria, diagnostic materials, software manuals, independent learning tasks and others [3]. For example, the following instructional guidelines have been elaborated to help teachers:

1. Digital transformation: wind of change.

2. Psychological security of the educational environment: expert assessment of design quality and support technology.

3. "Boiling point": blended learning - technology of the XXI century.

4. Time run into the digital education. The School of the Future.

5. Modern technologies for contemporary upbringing.

All these books are available on the Institute's website.

Any educational program of supplementary vocational education offered by the Institute contains the practice-oriented module "Digital Educational Technologies" with the volume of 8 hours.

However, it is essential to acknowledge the fact that up until recently the content-related vector of the module was shifted towards involving digital tools in the classroom work, for example: "OpenSchool", "IClass", "Phisicon" and so on. It was also biased towards using QR-codes, plickers, working with Google forms and services, creating subject teachers' sites as a safe educational environment for the student. At the same time, the use of remote educational technologies was considered as a technology compensating for shortcomings of the traditional lesson, extending it (for instance, for students who do not have an opportunity to attend a general education institution (in case of parents working abroad, professional practice of sport, weak health, trauma and so on); for students with special educational needs (talented, having difficulty in studies and others)), and, by way of exception, as a compensation for shortcomings of the educational process structuring (lack of specialists).

The modern content of the module is aimed at active application of efficient digital tools by teachers at schools. Teachers taking the courses are familiarized with the digital technology opportunities for individualization of the learning process, raising of the student's incentive, lightening of routine work (for instance, academic progress and reports monitoring, work checking). The module is intended to help the contemporary teacher with achieving key learning objectives, which cannot be attained today by means of traditional technologies.

In the midst of active introduction of remote technologies socially active parents started asking questions concerning legitimacy of the use of "e-learning" and "remote educational 
technologies". It is important to note that the legitimacy of the processes is determined by Federal law No. 273-Ф3 “On Education in the Russian Federation” of December 29, 2012, decrees, letters of the Ministry of Education and Science and Ministry of Enlightenment of Russia, methodological recommendations, specifying the procedure of e-learning and remote educational technologies application by organisations [2].

In such a challenging situation the Institute offers the scientific and methodological support for teachers and information support for parents on the issues concerning the use of remote educational technologies in the educational process. There are webinars, training workshops, consultations held on a regular basis on the Institute's open electronic platforms, such as "Virtual Onsite Training" and "Methodological Support in Organizing E-Learning".

The parents' meeting with representatives of the Ministry of Education and Science of the Republic of Tatarstan and specialists in the sphere of pedagogy and psychology has got a generous response (over 9 thousand views). The meeting was organized within the framework of "Open Class" project, initiated by Tatarstan Institute of Education Development, which was devoted to the problem of psychological support for parents within the social isolation period (access mode: https://ieml.ru/openclass).

Assurance of high quality and availability of implemented academic programs are the key priorities for the educational process organized both in the traditional format, and in the format involving remote educational technologies.

The binary learning effect of the remote educational technologies should be noted: not only the content, but also the process itself is educational by nature, plus, not only for the student, but also for the teacher. The post-course monitoring of teachers taking the advanced training courses in the distance learning mode during the pandemic period testifies that the following professional information and communication competences are evolving in the teacher:

- network communication;

- $\quad$ information and media literacy;

- ability to organize activities in the Internet, including that in the format of a distributed project group;

- digital ethics and digital hygiene;

- technical problem resolution, particularly, by requesting technical support;

- $\quad$ ability to use training equipment, mobile applications and other digital learning tools during classes;

- mastering new approaches to plotting the curriculum content; learning individualization;

- $\quad$ student feedback arrangement;

- ability to select digital educational technologies and electronic learning tools;

- planning and organizing the student's independent activity in the digital educational environment;

- $\quad$ organizing assessment in the digital educational environment, such as "inclusive assessment";

- $\quad$ intercommunication with students' parents using network tools.

The process of remote educational technology introduction cannot be successful without preliminary organizational work, engaging not only teachers and school management, but also students and their parents.

We have developed a generalized algorithm:

- inform the educational process participants about forthcoming events;

- $\quad$ select an electronic platform;

- hold teaching events for all the educational process participants (teachers, students, parents); 
- $\quad$ organize monitoring for identification of additional support objects;

- $\quad$ organize monitoring for identifying technical capabilities of the educational process participants;

- school management offers individual support in work with electronic platforms;

- school management renders assistance to the educational process participants with a view to ensure the respective technical capacity level;

- $\quad$ organize a consultative and technical support service;

- monitor the educational process participants: class attendance, satisfaction level.

The remote educational technologies represent a supplement to technologies and methods traditionally used by teachers. However, in some cases they serve as an alternative, which permits the teacher to focus the educational process on educational needs, demands and interests of a concrete student, avoiding interruption of the self-education process in the rapidly and unpredictably changing conditions of the modern life.

In such a way, the scientific and methodological support of the process of the teacher training for digital transformation of the educational process developed in the Institute takes into consideration a combination of informal and non-formal education, e-learning and remote educational technologies. Thus, the major part of supplementary vocational education programs is implemented on the basis of distance learning technologies, which ensure: content personalization; diversity of attendance modes and multi-format of individual educational routes (with predominating micro-modular formats); improvement of availability and expansion of the user coverage geography. We are currently developing an innovative advanced training model, which implies that the course participants pass problem/topicrelated cycles of onsite mini-trainings built into their individual educational routes, taking into account the digital educational environment.

Already formed is a social network covering all the age and position categories. It has been designed on the basis of available Internet resources and a specially created digital platform. The professional social network is functioning on foot of "we-learning" model ("learning organisation"), thus providing a broad spectrum of opportunities for non-formal and informal teacher education (discussing problematic issues, sharing experience, mutual consulting, joint research, non-formal peer assessment and expertise of projects etc.). In our understanding, the development prospect of the contemporary school is directly connected to creation of a high-quality digital environment. To achieve this purpose the teacher must be prepared for creating it. The mission of all institutes of education development consists in educating a modern teacher, ready to work with any technologies in the digital educational environment.

\section{References}

1. N. G. Rozlomiy, Methods and technologies of teaching special disciplines (Publishing house: Primorskaya State Academy of Agriculture, p.132, 2014)

2. V. P. Kashitsin, Research into the digitization process in the general education system of Russia (National and Foreign Pedagogy, V. 1, No. 3 (68), pp. 52-65, 2020)

3. M. G. Skalozubov, Forming a socially oriented personality of a student in institutions of supplementary education system: (Thesis of... Candidate of Pedagogic Sciences: 13.00.01 Kazan, 207 pp., 2007)

4. I. A. Abdullin, E. V. Azeeva, I. M. Aytuganov and others; edited by E. A. Korchagina, Scientific and methodological support and implementation technology for interrelations between educational institutions and enterprises - staff orderers: scientific and methodological guide (Kazan: Kazan National Research Technological University (KNRTU), 202 pp., 2010) 